\title{
Новые формы лука шалота в условиях Северо-Востока
}

\section{В.М. Мотов, А.В. Денисова, М.В. Мотова, О.А. Чеглакова}

Представлены результаты работы лаборатории селекции овощных культур ФГБНУ «Федеральный аграрный научный центр Северо-Востока имени Н.В. Рудницкого» по культуре лука шалота. Изучены и отобраны сортообразцы лука шалота. Установлено, что сортообразцы: АСТ- 117, АСТ-83, АСТ-118, АСТ-80, АСТ-88 обладают стабильно высоким урожаем и в дальнейшем могут использоваться в селекции и семеноводстве при вегетативном размножении.

Ключевые слова: лук шалот, перспективные сортообразцы, селекционное испытание, селекция, продуктивность, индекс формы, урожайность.

Л ук шалот получил широкое распространение как овощная культура во многих странах мира. Его выращивают в Западной Европе, в Англии, Нидерландах, Дании, Германии, Чехии, Франции, где созданы его селекционные сорта [1]. В России лук шалот выращивают во многих регионах, преимущественно в ЛПХ, чаще всего используют сорта местной селекции

Особенно велико значение этой культуры для средних и северных регионов Сибири и Урала, для которых характерен короткий период вегетации, длинный световой день и продолжительный осенне-зимний период. В таких условиях требуются сорта луковых культур и приемы выращивания, которые способствуют быстрому и более раннему, чем у лука репчатого, формированию хорошо вызревших крупных луковиц, лежких, с длительным периодом сохранности, но в то же время способных прерывать покой, при выгонке в защищенном грунте [2].

Лук шалот ценят за вкусную, сочную зелень, которая долго не грубеет и отличается особой нежностью. Окраска зелени может быть разных оттенков: от светло-зеленых до насыщенных изумрудных. Сама луковица не особо крупная - 20-50 г. Острые сорта лука шалот подлежат долгому хранению после уборки урожая и могут сохраняться до двух лет.

Возможно размножение лука шалота как семенами, так и вегетативно - луковицами. Из донца луковицы, которую используют для посадки, может образоваться несколько луковичатковости и формированию так называемого «гнезда» дает возможность чек. Способность растения к многоза- получить массу зеленых листьев и луковицы [3, 4, 5, 6].

Цель работы - интродукция и адаптация западно-европейских и азиатских сортообразцов к условиям Северо-Востока Европейской части РФ, а также создание на их основе новых сортов и гибридов лука шалота. Задачи: изучение перспективных сортообразцов лука шалота в условиях Северо-Востока России, а также определение их продуктивности и биохимического состава; определение вегетационного периода на основе фенологических наблюдений; выделение многозачатковых образцов салатного назначения и с длительным периодом хранения, способных генеративно размножаться.

Сортообразцы лука шалолекционного питомника Научнопроизводственной

фирмы «Агросемтомс» (начало сбора 2009 год). Селекционный участок располагается на дерново-подзолистой почве в Оричевском районе Кировской области. Почва обладает высоким агрофоном, в пахотном слое почвы: содержание гумуса 4,35\%, содержание $\mathrm{pH}_{\mathrm{kcl}}=4,78$, содержание (по Кирсанову) $\mathrm{P}_{2} \mathrm{O}_{5}>$ \section{0 мг, $\mathrm{K}_{2} \mathrm{O}>250$ мг на кг почвы. \\ Таблица 1. Биометрические показатели лука-шалота (2017-2018 годы)}

\begin{tabular}{|c|c|c|c|c|}
\hline $\begin{array}{c}\text { № } \\
\text { сортообразца }\end{array}$ & Высота (h), см & Диаметр (d),см & Отношение $\mathrm{h} \backslash \mathrm{d}$ & $\begin{array}{c}\text { Ширина шейки, } \\
\text { мм }\end{array}$ \\
\hline Контроль & 3,9 & 5,4 & 0,7 & 0,8 \\
\hline ACT-117 & 7,0 & 4,4 & 1,6 & 1,0 \\
\hline ACT-83 & 5,6 & 5,3 & 1,1 & 1,0 \\
\hline ACT-118 & 9,7 & 3,6 & 2,7 & 0,3 \\
\hline ACT -80 & 3,5 & 4,5 & 0,7 & 0,9 \\
\hline АCT-88 & 6,1 & 3,6 & 1,7 & 0,6 \\
\hline
\end{tabular}
шалот Красносельский. Это раннеспелый сорт рекомендованный для выращивания луковиц методом вегетативного размножения. Луковица Красносельского поперечно-узкоэллиптическая, массой от 30 до 50 г. Сухие чешуи - красные, сочные красноватые. Сухих чешуй - 4-5 шт. Шейка тонкая. Сорт пяти-семизачатковый, в одном гнезде - 6-9 луковиц, иногда до 12 шт. Вкус полуострый. Урожайность - 2,5-3,2 кг/м². Вызреваемость луковиц перед уборкой - 100\%. Сорт пригоден для хранения: лежкость луковиц хорошая 7-8 месяцев, сохранность - 86\%.

В исследованиях использовали общепринятые методики [7, 8, 9].

В 2017 году погодные условия в значительной степени влияли на продолжительность вегетативного роста сортообразцов лука шалота. Однако близкая к норме среднесуточная температура в течение вегетационного периода незначительно повлияла на вызреваемость луковиц. Окончательно луковицы вызрели на 68-81 день.

Погодные условия в 2018 году характеризовались высоким отклонением от нормы с перепадами температуры в течение всего вегетационного пета были предоставлены из кол-

За период работы с 2017-2018 годов были выделены шесть наиболее пластичных к местным условиям сортообразцов лука шалота различного эколого-географического происхождения, разной формы и окраски. Каждый образец первоначально прошел клоновый отбор, генеративное размножение (инцухт в изоляторах) и вегетативное размножение.

За стандарт в исследованиях был принят внесенный в реестр РФ лук 


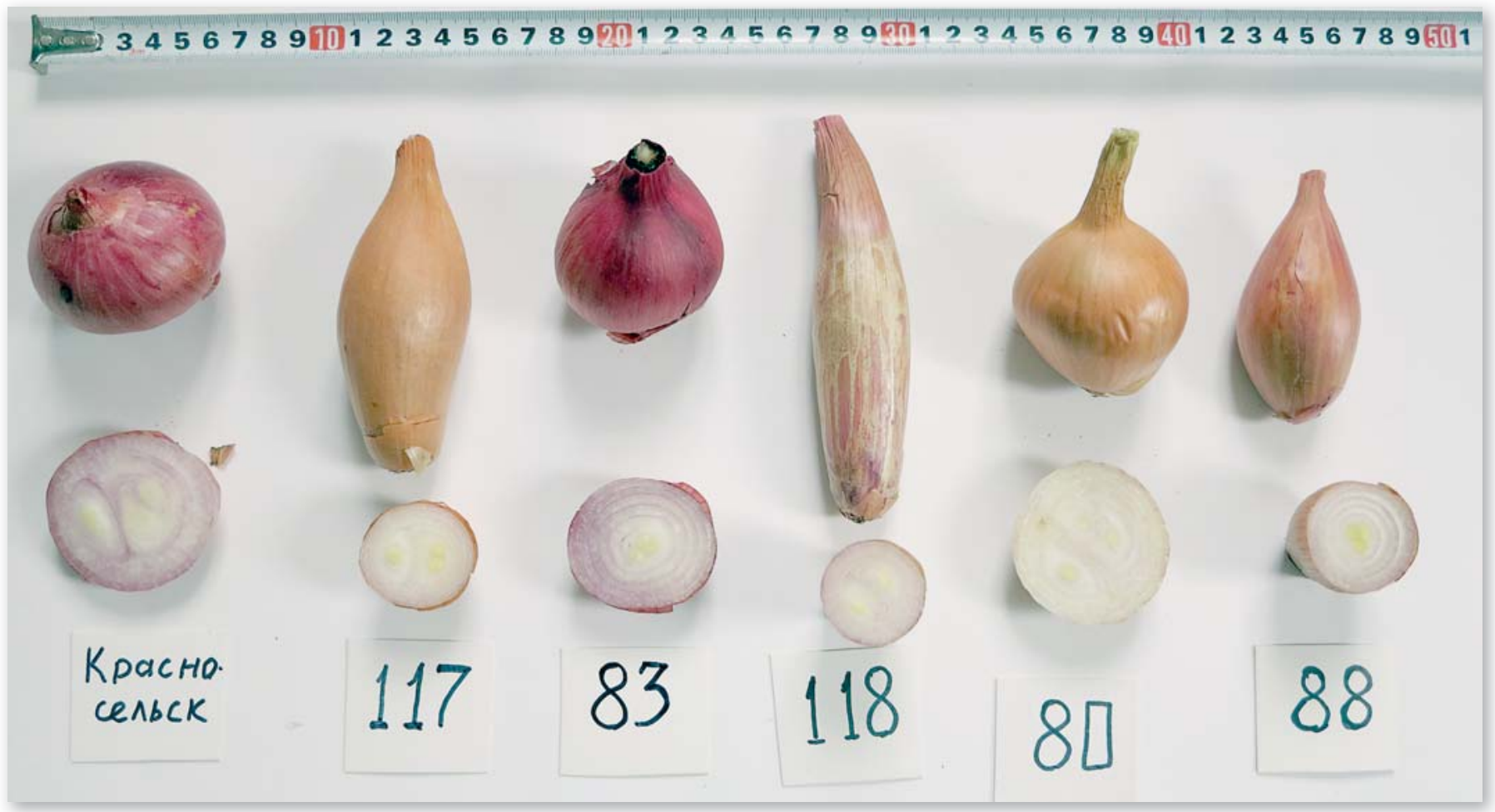

Рис. 1. Сортообразцы лука шалота

риода, что в значительной степени ускорили созревание луковиц. С момента посадки лука шалота до полегания пера прошло 53-59 дней.

Согласно данным за два года, наибольшая высота луковицы отмечена у сортообразцов: АСТ-117 и АСТ-118. Наименьшая высота отмечена у сортообразца АСТ-80, однако по отношению высоты к диаметру $(h \backslash d)$ он был на уровне контроля (табл. 1).

Наибольший диаметр луковиц был у контрольного варианта 5,4 см., минимальный у АСТ-88, при отношении $\mathrm{h} \backslash \mathrm{d} 1,7$.

Форма и окраска луковицы имеет большое значение на потребительском рынке. Форму луковицы определяли отношением высоты к диаметру, дающим числовое выраже- ние - индекс, и по шкале (от плоской до удлиненной).

Были выделены сортообразцы округлой формы: АСТ-83 и АСТ-80. Сортообразец АСТ-88 отнесли по форме к широкоэллиптическим. Отнесли в группу с эллиптической формой АСТ-117, АСТ-118. (Индивидуальный отбор из французского сорта Zebrune) Форма и цвет сортообразцов: АСТ117, АСТ-118 были признаны наиболее привлекательными для потребителя и удобными для производителя (рис.1).

Наибольшая урожайность с $1 \mathrm{M}^{2}$ была получена у трех сортообразцов: АСТ-83-4,9 кГ, АСТ-88-4,6 кГ, АСТ118-4,2 кг; это выше, чем в контроле (табл. 2; рис. 2) и обусловлено большой средней массой одной луковицы, не смотря то, что количество лу-

Таблица 2. Продуктивность и индекс формы лука-шалота (2017-2018 годы)

\begin{tabular}{|l|c|c|c|c|}
\hline $\begin{array}{c}\text { № } \\
\text { сортообразца }\end{array}$ & $\begin{array}{c}\text { Урожайность, } \\
\text { КГ } \backslash \mathrm{M}^{2}\end{array}$ & $\begin{array}{c}\text { Среднее кол- } \\
\text { во луковиц в } \\
\text { гнезде, шт }\end{array}$ & $\begin{array}{c}\text { Средняя масса } \\
\text { луковицы, } \Gamma\end{array}$ & Индекс формы \\
\hline Контроль & 3,6 & 6,3 & 37 & 0,7 \\
\hline АСТ-117 & 3,6 & 4,2 & 55 & 1,6 \\
\hline АСТ-83 & 4,9 & 6,4 & 50 & 1,1 \\
\hline АСТ-118 & 4,2 & 4,0 & 65 & 2,7 \\
\hline АСТ-80 & 3,3 & 5,5 & 42 & 0,7 \\
\hline АСТ-88 & 4,6 & 7,6 & 39 & 1,7 \\
\hline НСР & 0,36 & & & \\
\hline
\end{tabular}

ковиц в гнезде было меньше, чем в контроле.

Количество луковиц в гнезде варьировало в зависимости от сортообразца: у АСТ-88 наибольшее количество луковиц в гнезде 7,6 шт., при средней массе одной луковицы 39 г; также выше контроля был образец АСТ-83 с количеством луковиц в гнезде 6,4 шт., при средней массе одной луковицы -50 г. Таким образом, в результате исследований мы наблюдали прямую зависимость между количеством луковиц в гнезде и весом одной луковицы (рис. 2, 3).

Химический состав лука зависит от многих факторов, в первую очередь от сорта, экологических условий и агротехнических приемов. По вкусовым качествам сорта лука делятся на три группы: острые, полуострые и сладкие или салатные, которые отличаются по содержанию в луковицах сухого вещества, сахаров и других веществ.

В результате биохимического анализа исследуемого материала было установлено, что по содержанию сухого вещества исследуемые сортообразцы лука шалота не превысили контроль - 18,98\%. Большее количество сухого вещества накапливают луковицы острых сортов - до $22 \%$, сладких сортов - около $10 \%$. Таким образом, все изучаемые об- 


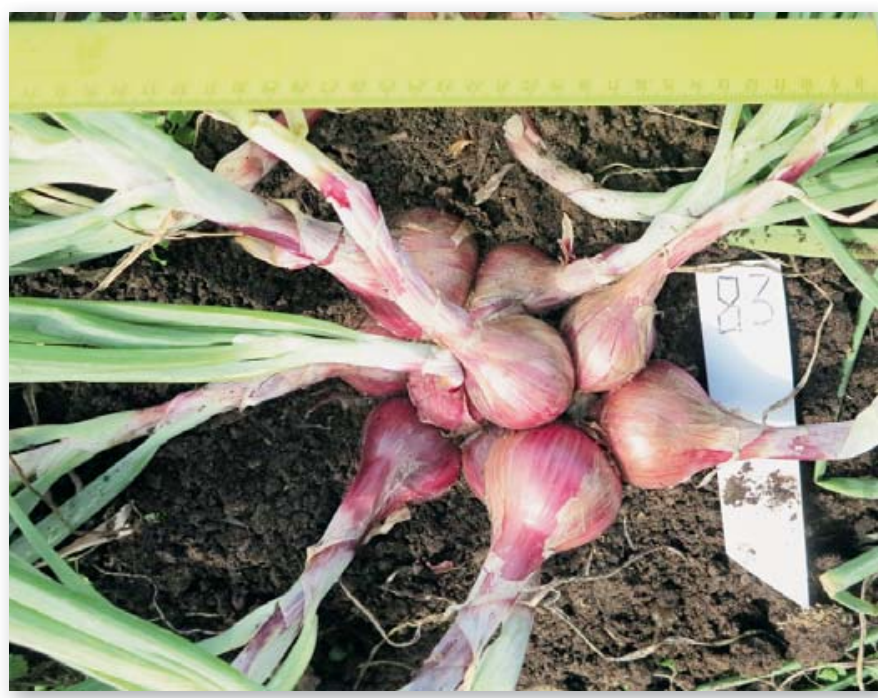

Рис. 2. Сортообразец АCT-83, внешний вид при вегетативном размножении

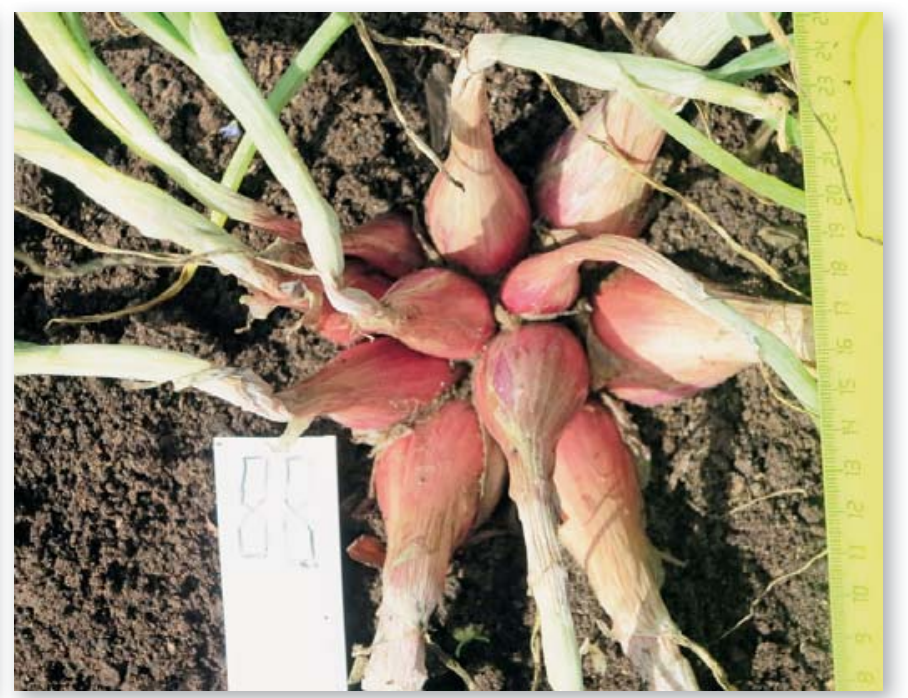

Рис. 3. Сортообразец АCT-88, внешний вид при вегетативном размножении разцы вместе с контролем мы отнесли к полуострым сортам лука шалота.

Для длительного хранения предпочтительней полуострые и острые сорта лука [7].

Высокое содержание сахаров один из критериев хорошей лежкости луковиц [1]. В наших опытах по содержанию сахаров ни один сортообразец не превзошел контроль 6,65\%, а сортообразец АСТ-118 накопил меньше всего сахаров - 4,22\%. По содержанию аскорбиновой кислоты контроль превысили сортообразцы: АСТ-118 с 12,54\%, АCT-88 c $11,00 \%$, АСТ-83 c $11,88 \%$.

Сладкий лук содержит больше воды, значительно меньше гликозидов, поэтому ощущение сладости у него более выраженное даже при небольшом количестве сахаров [1]. Название группы «сладкие сорта» не означает, что они содержат больше сахаров (они содержат их значительно меньше, чем полуострые и острые), но они содержат меньше эфирных масел, которые и определяют остроту вкуса. Луковицы сладких сортов имеют среднюю плотность, содержат больше воды, из-за чего внутренние чешуи у них более сочные [10],

Общая тенденция зависимости содержания сухого вещества и сахара в исследованиях видна достаточно ясно: сортообразцы, отличающиеся высоким содержанием сухого вещества, накапливают больше сахаров

На основе исследования сортообразцов лука-шалота в 20172018 годах была установлены привлекательные для потребительского рынка и для покупателя сортообраз- цы с эллиптической формой луковиц АСТ-117 и АСТ-118, а также образец АСТ-88 с широкоэллиптической формой и красивой окраской.

Наши исследования показали, что изучаемые сортообразцы АСТ117, АСТ-83, АСТ-118, АСТ-80, АСТ88 обладают стабильно высоким урожаем и в дальнейшем могут использоваться в селекции и семеноводстве при вегетативном размножении. Сортообразцы: АСТ-83 и АСТ-88 выделены как наиболее перспективные по хозяйственно полезным признакам и их можно рекомендовать для дальнейшего сортоиспытания.

\section{Библиографический список}

1.Пивоваров В.Ф., Ершов И.И., Агафонов А.Ф. Луковые культуры. М., 2001. 500 с.

2.Гринберг Е.Г., Сузан В.Г. Штайнерт Т.В., Лук шалот. Научно-практические рекомендации. НовосибирскЕкатеринбург, 2016. 45 с

3.Круг Гельмут. Овощеводство. М., 2000. 607 с.

4.Водянова О.С. Луки. Алматы, 2007. 367 с.

5.Гринберг Е.Г., Ванина Л.А., Сузан В.Г. Лук шалот в Сибири и на Урале. Новосибирск, 2007. С. 115-117. 6.Гринберг Е.И., Жаркова С.В., Ванина Л.А., Сузан В.Г., Шлыкова Е.А., Денисюк С.Г. Научные основы интродукции, селекции и агротехники лука шалота в Западной Сибири. Новосибирск: Изд-во НГАУ, 2009. 207 c.

7.Ершов И.И., Агафонов А.А., Алексеева М.В. и др. Методические указания поселекции луковых культур. М.: Росельхозакадемия, 1997. 123 с.

8.Литвинов С.С. Методика полевого опыта в овощеводстве. М.: Россельхозакадемия, 2011. 648 с.

9.Методика Государственного сортоиспытания сельскохозяйственных культур. Вып.4. Картофель, овощные и бахчевые культуры. 1975. 256. С. 5.

10.Немтинов В., Салатный лук сорт Ялтинский Плюс перспективный инновационный продукт Крыма // Овощи России. 2018. № 3. С.43-46.

\section{Об авторах}

Мотов Виктор Михайлович, канд. c. - х. наук, зав. лабораторией селек- ции овощных культур.

E-mail: v-motov@list.ru

Денисова Анна Валерьевна, канд. с. - х. наук, н.с. лаборатории селекции овощных культур

Мотова Маргарита Викторовна, канд. биол. наук, н.с. лаборатории селекции овощных культур

Чеглакова Оксана Александровна, м.н.с. лаборатории селекции овощных культур

ФГБНУ «Федеральный аграрный научный центр Северо-Востока имени Н.В. Рудницкого»

New forms of shallots in the North-East of Russia

V.M. Motov, PhD, head of the vegetable

crops breeding laboratory.

E-mail:v-motov@list.ru

A.V. Denisova, PhD, research fellow of the vegetable crops breeding laboratory M.V. Motova, PhD, research fellow of the vegetable crops breeding laboratory

O.A. Cheglakova, junior research fellow of the vegetable crops breeding laboratory State Scientific Institution Federal Agrarian Research Centre of the North-East

Summary. The work results of the laboratory of vegetable crops selection Federal Agrarian Research Centre of the North-East in shallot onion culture are presented here. Selection and research of the sort samples of shallots have been conducted. It has been established that the sort samples AST-117, AST-83, AST-118, AST-80, AST-88 have a consistently high yield and can be used in selection and seed production for vegetative propagation in the future.

Keywords: shallot onion, promising samples, selection testing, selection, productivity of shallot onion, form index, shallot onion yield, biometric measures, phenological observations. 